\title{
Introduction: a need for better anti-corruption strategies in fragile states
}

For at least the last decade, the international community has increasingly stressed the need to help fragile states out of the vicious cycle of conflict, poverty and poor politics. Aid agencies, particularly the multilateral ones, have taken a lead role in support efforts. All acknowledge that corruption is detrimental to the future stability and progress of these countries. However, a closer look beyond the formal declarations quickly reveals that agencies have weak strategies for how to curb corruption in these contexts, and that even where a roadmap is provided it is often not followed in practice at the country level.

Aid agencies face a great challenge working in fragile states. These countries are not only poor, but are often left with deep societal scars, dysfunctional institutions, political rivalry and low levels of trust after periods of conflict and violence. Hard-earned progress can easily be reversed if fighting breaks out again. Corruption makes it even more difficult for fragile states to escape fragility. The focus of this book is to find better ways to curb corruption is such difficult environments.

These challenges have been described by the author and others before. Marquette (2003) provides an early analysis of the World Bank's challenges in the anti-corruption field. Together with Nils Taxell, the author has written policy papers for the European Union (EU) and the United Nations Development Programme (UNDP) recommending a change in strategy (Johnsøn and Taxell 2015; Taxell and Johnsøn forthcoming). This book is, however, the first systematic comparative analysis. The main claim is that bureaucratic pathologies within aid agencies have a profound impact on the way in which corruption is tackled in fragile states. Solving these basic organisational dysfunctionalities within aid agencies is hard but necessary, regardless of the level of political will to curb corruption in national governments.

Speaking to a programme manager for a multilateral aid agency in Afghanistan, I realised that any analysis of anti-corruption efforts needs to distinguish between knowing what to do and having the capability to actually do it. This book argues that aid agencies face problems on both fronts. Their strategies differ, so they disagree on what to do. Overall, 
they miss an emphasis on the importance of the timing of reforms, the level of capability required to implement them and adaptation to local contexts and politics. When it comes to their own capacity to implement their respective strategies, it is remarkable how they face exactly the same challenges. This statement from the programme manager captures the essence of 57 other interviews I had with similar people:

I don't think we were provided with very much guidance on how to analyse the context and how to target interventions, which is probably why you are going to end up with a lot of project documents and projects around the world from conflict and non-conflict countries looking quite similar.

Staff working in aid agencies know that the reforms and programmes they support are not ideal. Intuitively, they know that corruption should not be tackled the same way in Afghanistan as in Croatia. So why do they not change their approach? Again, the answer lies inside the aid agencies themselves.

This book is the first comparative study of three major multilateral aid agencies' strategies to control corruption. It analyses and compares the anti-corruption approaches of the World Bank, the EU and UNDP in countries marked by fragility, focusing specifically on Afghanistan in the last chapter. The point of departure is that aid agencies increasingly consider anti-corruption activities important for reducing fragility. Fragile states account for a large proportion of development aid budgets. ${ }^{1}$ Aid agencies are therefore engaged in anti-corruption activities in a large number of fragile states (Norad 2008, 20). Recently, policy makers have re-framed development goals for fragile states towards stability, to address their special characteristics: weak institutions and governance; low capacity and legitimacy in government; and vulnerability to violence. Governance and anti-corruption interventions play a crucial role in reducing fragility and building legitimate and resilient institutions.

The analysis is based on 58 interviews with senior staff members of the aid agencies, consultants charged with the implementation of reforms, evaluators, and representatives from government and civil society in Afghanistan. The study also analyses a large amount of strategy documents, official evaluations, policy papers and programme documents. The review reveals a clear difference between stated policies on the importance of controlling corruption in fragile states and the reality on the ground, where anti-corruption is often not prioritised by decision makers when these objectives compete with, for example, security or political objectives. 
Good strategies need a clear problem definition. Fragility is not a measure of the early stages of development in a country, yet definitions of fragility from the World Bank and the EU are mainly based on a country's performance in terms of traditional development outcomes, such as GDP. As such, they fail to capture the defining challenges of fragile states. UNDP's definition comes closer, by recognising the role of crisis, conflict and other forms of vulnerability. Agencies should develop, restore or strengthen policies and institutions that promote the legitimacy of shared governance structures, safeguard human security and wellbeing, and reduce the risk of conflict. The aim is to have resilient institutions that can weather the storms.

All agencies have the same definition of corruption, but as shown in Chapter 1 this definition - abuse of public office for private gain - is not suitable for contexts where Weberian ideals of bureaucratic behaviour and the distinction between public and private spheres are blurred by patronage, lack of the rule of law, and politicised administrations. Agencies' definitions of corruption often do not make sense in fragile contexts. This study sees corruption as an act that distorts the political process of building stable, resilient institutional structures. This means that, for example, minor theft is not considered corruption, unless it is part of a systemic rent-extraction mechanism.

The analytical perspective is based broadly on public administration and organisation theory, and more narrowly on the literature on the bureaucracies of international organisations (Barnett and Finnemore 1999; Peters 2001). It complements the limited number of studies looking at aid agencies' strategies and implementation practices as explanatory variables for development outcomes (Pritchett et al. 2010). The three aid agencies are characterised as organised anarchies. The main characteristics of organised anarchies are: problematic preferences, unclear technology and fluid participation (Cohen et al. 1972, 1). This complements Lindblom's (1959) framework of the policy process, which is used to explain how decision making within the agencies is often based on an incremental muddling through approach rather than a rational means-end analysis.

By taking a public administration perspective, studying the virtues and pathologies of international aid organisations, the analysis explores this black box in evaluating the effectiveness of anti-corruption reforms: the role of aid agencies themselves, the role of implementation and the politics of reform. This is a refreshing departure from the dominant academic perspective that is rooted in the economics literature and focuses on principal-agent relations and transaction cost analysis. A look inside the aid agencies shows that these organised anarchies share 
the following constraining characteristics: (a) anti-corruption policy units are minimally staffed and there are few full-time advisors at the country level, (b) anti-corruption and state-building/fragility units are uncoordinated, (c) structures are decentralised with considerable idiosyncratic decision making, and (d) inadequate human and financial resources, disbursement pressures, rigid procedures and risk aversion hinder effective implementation.

If aid agencies design and implement their own anti-corruption strategies well, they may make a positive contribution to reducing corruption and fragility in partner countries. However, many other factors will play a role in such reduction, and often a much larger role. The military, transnational organised crime, the drug trade, local politics, and so on are key factors, and some readers may find the focus on aid agencies too narrow. In order to avoid overplaying the role of aid agencies in reducing corruption and fragility in fragile states, the measure of success or failure for this study is kept very simple: aid agencies are seen to succeed if they manage to align their anti-corruption and state-building policies internally, and to implement their strategies according to plan. Whether or not that will lead to less corrupt and more stable countries is an empirical question that is not possible to answer at this stage. As discussed below, to know what works and why, one has to distinguish between theory and implementation failure. We cannot know whether aid agencies got the theory right before they fix the implementation failures.

When strategies were followed and resources were adequate, aid agencies achieved results. In Afghanistan, areas of the public financial management system were strengthened considerably, the Joint Monitoring and Evaluation Committee played an important role in investigating high-profile corruption cases such as the Kabul Bank scandal, and Integrity Watch Afghanistan is a role model for other NGOs in fragile states. However, disjunctures are too often found between strategy and practice in the aid agencies' anti-corruption efforts. Policies for anticorruption and state building are often disconnected or incoherent, and implementation challenges prevent strategies from translating into results. Those charged with formulating, implementing or evaluating anticorruption reforms should pay attention to strategy-practice disjunctures and their implications for the effectiveness of reforms to learn what works and why in anti-corruption. Still, the study shows that where the will and resources exist, it is possible to change practices within aid agencies. For example, the World Bank has come quite far in mainstreaming corruption concerns and anti-corruption measures into countrylevel strategies, which was an early strategic goal, and the Governance 
Partnership Facility serves as an example of the importance of having finances for country-level governance and anti-corruption advisors.

Implementation failure plays an important role in explaining aid agencies' poor track record with anti-corruption reforms in fragile states. However depressing this finding may sound, it is in fact quite positive. If efforts to curb corruption have failed mainly because implementation was lacking the adequate financial or human resources, or because of internal organisational barriers, then the cancer of corruption can be removed with adequate care. This is not to say that political will and local capacity do not matter, but that these are not the only variables of importance to the success or failure of aid agencies' anti-corruption efforts.

\section{AFGHANISTAN: SO MUCH MONEY, YET LITTLE FOCUS ON CORRUPTION}

This book delivers a global analysis of the anti-corruption strategies and practices of the multilateral aid agencies. To contextualise the findings, aid agencies' experiences in Afghanistan are analysed in more depth. Trillions of US dollars have been invested in state-building efforts since 2001. However, anti-corruption activities were not discussed until 2005 and were not actively pursued before 2006. Today, anti-corruption activities are still few and far between, despite reports of massive corruption and waste in both government and aid spending. A realisation is emerging that stability and development in Afghanistan are difficult to achieve if one does not at least try to tame what has been characterised as a 'mafia state' (The Economist 2009). Sarah Chayes (2015) has also pointed to the transnational drivers and consequences of corruption in Afghanistan, making the argument that Afghan and global security cannot be separated. Her analysis focuses more on the role of the military than on aid agencies. She shows that government corruption promotes extremism and undermines security, and illustrates well the flawed thinking of both military and civilian actors until at least 2010: 'first let's establish security, then we can worry about governance.' The failure to understand that poor governance caused insecurity was the original sin (Chayes 2015, 43). The question remains, however, of how external actors can work to reduce corruption in such contexts.

The Afghan experience illustrates how development efforts are jeopardised by widespread corruption, within both government and aid systems, and the difficulties of implementing anti-corruption strategies in a highly fragile and politically sensitive environment. It also shows that the poor results of aid agencies' efforts to strengthen country systems to 
control corruption were to be expected, as agencies had a late start, did not follow their own recipes and devoted few resources to anti-corruption relative to the overall budget envelope.

\section{TWO UNALIGNED AGENDAS: FIGHTING CORRUPTION AND REDUCING STATE FRAGILITY}

Corruption is believed to have corrosive effects on societies. Over the past two decades, aid agencies have increasingly seen the fight against corruption as an important element in promoting wider goals of economic development and poverty eradication in developing countries (Doig and McIvor 1999; Marquette 2003; Rose-Ackerman 2013). Recently, policy makers have framed the development goals for fragile states around issues of stability, for example via the New Deal agreement (OECD 2011). The rationale is that fragile states have special characteristics: weak institutions and governance; low capacity and legitimacy in government; and a vulnerability to violence (World Bank 2006a, xxiii; 2011a, xi-xvii; Putzel and Di John 2012, 8; UNDP 2012a, 16-19). Rather than focusing on economic growth or poverty reduction, one must first reduce external and internal 'stresses' and build legitimate and resilient institutions (World Bank 2011a, xi). The UN's new Sustainable Development Goal number 16 on 'Peace, Justice and Strong Institutions' builds on the same logic, seeking to reduce both violence and corruption in society by building inclusive and just institutions.

So, aid agencies recognise that corruption corrodes stability, as it undermines the social contract, prevents effective delivery of basic services and feeds violence. They know they have to change the way they work in fragile contexts (European Council 2006b, 5; World Bank 2011a, xii; UNDP 2012a, 11). However, practitioners and academics still disagree about the ability of anti-corruption reforms to foster stability, and in particular about which specific mechanisms are most effective. Fundamentally, it is not clear whether or how anti-corruption activities should be different in fragile states. Aid agencies have recognised that corruption matters for fragility, but have not formulated whether or how anticorruption matters for stability.

Scholars have observed a deep tension between the traditional statebuilding agenda and the modern anti-corruption agenda (June and Heller 2009). The state-building agenda has its roots in the modernisation theory literature, which argues that corruption is not a primary concern in the early state-building phase. The overall philosophy is 'state-building first, anti-corruption second'. This contradicts the anti-corruption literature, 
which finds that controlling corruption is an essential part of building a legitimate, effective state (Johnston 2010; Marquette 2011). Efforts to combine the two perspectives are pursued, but appear difficult to operationalise. This has resulted in fragmentation and a situation where aid agencies, after more than a decade of intensive engagement in fragile states, still have very limited success to show in the area of anticorruption in such contexts (UNDP 2010b, 52). Both agendas regard institution building as the solution to problems and fail to recognise the importance of forces outside the countries in question. They often implicitly assume that the drivers of corruption and fragility primarily come from the societies themselves, not from the outside world.

The pathological effects of aid agencies' bureaucracies are assumed to adversely influence most types of anti-corruption reforms, in all countries. However, the consequences are likely to be worst for contexts where the capacity and political will of the recipient government are at their lowest, and agencies themselves face additional operational constraints in terms of security and recruitment/staff retention. The focus is therefore on anti-corruption approaches for fragile states. Most development practitioners struggle when working in fragile contexts due to undifferentiated, conflicting or non-existing policies and programmatic guidance. Instability is considered harmful; however, 'amidst all this focus on instability, there is less critical reflection on practical policies and applied practices to promote stability' (Muggah et al. 2012, 1). This necessitates a better understanding of the nexus between corruption and fragility.

\section{WHY FOCUS ON AID AGENCIES?}

Aid agencies spend vast amounts of money in fragile contexts with high corruption risks. The World Development Report 2011 made it clear that to succeed in any area of development in fragile states, strategies can no longer be 'business as usual'. This was echoed by the New Deal for Engagement in Fragile States at the fourth high-level forum for aid effectiveness. Scholars are increasingly recognising that corruption manifests itself differently in fragile contexts than in other contexts, and that corruption control needs to be done differently. Yet, aid agencies have not adapted their organisational strategies (Zaum et al. 2015).

The World Bank, the EU and UNDP take different approaches to anti-corruption work. This is reflected in their organisational policies, strategies, programme designs and implementation practices. There are also striking commonalities, particularly in regard to organisational 
challenges for the effective implementation of strategies. Why would these agencies adopt different approaches to the same problem? Also, if they indeed face the same challenges, these might be systemic problems for aid agencies in general.

Anti-corruption interventions by aid agencies have generally been seen to fail by most academic observers, and it is often assumed that this is due to the wrong strategies, in other words theory failure (Johnsøn et al. 2012). However, an alternative explanation is possible: that interventions fail not because they are based on flawed reasoning, but because they are inadequately implemented. This explanation deserves further exploration and necessitates an analysis that looks inside the aid agencies.

Traditionally, studies have focused on the impact of corruption or the different manifestations of the phenomenon, not on the ways in which aid agencies work to reduce corruption when collaborating with interlocutors from government, civil society or other aid agencies. Few studies on anti-corruption undertake an actual organisational analysis to identify policies, institutional structures, processes, formal and informal incentive systems, and implementation dynamics that promote different organisational behaviours (Klitgaard 1988, 156-89, 204-5). This book analyses how organisational factors within the agencies, and their potential bureaucratic pathologies, affect anti-corruption efforts at both the strategy and implementation levels, but it also incorporates explanatory variables around aid as a modality, such as the absorption capacity of recipient governments and civil society organisations, local ownership, donor disbursement constraints and donor coordination (Svensson 2005a). It thereby opens up what has so far largely been a 'black box' in analysing the effectiveness of anti-corruption reforms: the role of the aid agencies themselves, the role of implementation and the politics of reform. ${ }^{2}$

\section{IMPLEMENTATION MATTERS AS MUCH AS DESIGN FOR STRATEGY}

The focus on both strategy and practice in implementation matters, as it enables the study of anti-corruption reforms to distinguish between theory failure and implementation failure. ${ }^{3}$ In essence, the failure of policy or programmes comes from either 'weak implementation, or in the case of smooth implementation, a weak theory regarding the types of activities and outputs needed in certain circumstances to bring about a desired effect' (Vaessen and Leeuw 2010, 146). Implementation failure refers to the inability of the interventions to perform the intended 
activities. Theory failure occurs when well-implemented activities do not produce the desired effects. ${ }^{4}$

By incorporating the possibility of implementation failure and strategy-practice disjunctures, the analysis advances and nuances the anti-corruption literature. Strategy-practice disjunctures may have two main forms: (a) inconsistencies between strategy propositions and programme designs, and (b) consistency between strategy and programme design, but inconsistency between programme design and practice in implementation.

At the strategy level, the study analyses whether aid agencies' strategies for anti-corruption are coherent with other organisational strategies, and show consistency over time. The key characteristics of the strategy for anti-corruption are explored, including whether a differentiated approach is taken towards fragile states. At the programme level, the study seems to determine whether programme designs are aligned with the strategic plan by considering variance in programme designs and the barriers to implementation, such as the available human and financial resources, and the impact of organisational structures, cultures and incentives. In short, do the aid agencies have the right strategies and are these strategies implemented according to plan?

Aid agencies often delegate implementation to national authorities, civil society organisations and consultancies. They allocate few resources to monitoring whether these agents implement their programmes well. This is a particular problem for anti-corruption programmes, where some government officials can have incentives to resist the implementation of measures that can harm their own interests. This link in the chain is obviously important, but the study finds that the chain breaks even before this point, namely when agencies formulate strategies and programmes themselves at the country level.

Governments' lack of political will is a common explanation for aid agencies' poor results in curbing corruption in fragile states. This is generally true, but not the full story. Factors that are completely within the control of aid agencies themselves also have a detrimental effect on the outcomes of their anti-corruption efforts in fragile states. There are problematic inconsistencies in the agencies' anti-corruption strategies, and significant incoherence between the agencies' strategies for anticorruption and those for fragile states. There are clear disjunctures between strategy propositions and programme design and implementation practices. In brief, agencies provide little strategic guidance on how to curb corruption in fragile states to their staff, and what little advice is provided is often not followed in practice. 
One reason for the strategy-practice disjuncture might be what has been labelled the design-reality gap, that is the mismatch between the expectations of the design and the realities on the ground (Heeks and Mathisen 2012). However, interviews with the people charged with the development of strategies and the actual implementation of programmes show a more complex picture, with problems emanating from the overall headquarters strategy level to the level of country strategies, as well as from the levels of design and implementation of individual programmes and projects. Although some failures can reasonably be attributed to a mismatch of design to the local context, this study shows that some organisational factors within the aid agencies also matter, irrespective of the local context. As mentioned above, the study identifies four common factors for the three agencies: lack of resources to implement strategic goals; bureaucratic competition and/or culture conflicts; disbursement pressures and perverse organisational incentives; and the lack of strong organisational centres, official policies and clear guidance on anti-corruption.

The problems identified in this study have damaging effects on some of the poorest countries in the world. It is impossible to establish a clear counterfactual scenario, but most would agree that ensuring aid agencies have the right anti-corruption strategies and that they implement them well is a worthwhile goal. Importantly, these problems are solvable, with the right mix of institutional commitment and individual grit. One example of how small efforts can initiate positive change is the report on the EU's anti-corruption approach that the European Parliament commissioned from this author in 2015. We illustrated how the organisation had built up much experience in fighting corruption as part of its Enlargement process, and how it had also recently played an increasingly large role within member states, but we stressed that the drive that had characterised these efforts and the knowledge that had been built up did not spill over to its development aid agenda (Johnsøn and Taxell 2015). The report touched a nerve and we were invited to present the report to the Parliament and the Commission on two occasions. During the last presentation, the Commission pledged to implement many of the recommendations in the report to strengthen its efforts in curbing corruption in its development aid operations. The role of the European Parliament was crucial in overcoming the initial scepticism towards the report. The World Bank and UNDP do not have the benefit of such democratic control organs to push reforms.

The rest of the book is structured as follows. Chapter 1 describes how our understanding of corruption, anti-corruption and fragility influences efforts to reduce corruption and fragility. Chapter 2 provides suggestions 
for how corruption is best prevented in fragile states, building on the most important current theories on how to curb corruption and prevent state fragility. Chapter 3 analyses aid agencies' current anti-corruption approaches in fragile states, comparing the World Bank, the EU and UNDP. Chapter 4 analyses the aid agencies' performance in Afghanistan. The conclusion presents the main policy implications of the analysis, and perspectives for future research on anti-corruption.

\section{NOTES}

1. Thirty per cent of overall ODA, according to the $\operatorname{OECD}(2011,1)$.

2. Marquette (2003) is one exception to this general trend.

3. The concepts of theory failure and implementation failure originate from the evaluation literature. Stame $(2010,372)$ provides an overview of the conceptual origin and development of these concepts.

4. This definition is based on the classic formulation by Edward Suchman (Weiss 1997, 41). 
Jesper Johnsøn - 9781784719715

Downloaded from PubFactory at 04/26/2023 11:56:22AM via free access 